\title{
Some Takeaways from the Pandemic
}

DIANE ZABEL

The Pennsylvania State University, University Park

dxz2@psu.edu

I am writing this introduction as my home institution is working hard to facilitate a full return to campus in August 2021. Many Ticker readers are also probably focused on this transition. The pandemic played a role to some extent in almost all of the articles in this issue.

Mihoko Hosoi's feature article, "Free Lunch? Vendor Offers during COVID-19," takes us back to the beginning of the pandemic when many of our libraries accepted free offers from vendors for electronic resources as we scrambled to support remote learning. This study discusses benefits, costs, and strategies for both parties (libraries and vendors). The article will remain relevant after the pandemic has ended since vendors may continue to offer free trials given the fiscal challenges that many libraries will face post COVID-19.

Abigail Morgan's article in the "Teaching and Learning" section is a lesson about the importance of agility. COVID-19 forced her to quickly adapt instruction to first-year undergraduate business students. This case study is impressive given the scale of instruction. While offering practical advice, the article also has a strong conceptual framework. The "Tips" section features an article by David Irvin on creating effective assignments to teach investment financial literacy. The author reminds librarians that collaboration and flexibility are two principles that should guide embedded librarianship. Will library spaces change because of the pandemic? The "Libraries by Design" section brings us Laura Walesby's fascinating interview with Larissa Fedoroff, an interior designer. This article is essential reading for any library planning enhancements to their spaces. It was great to learn that there are inexpensive strategies for improving space. Since planning and assessment are key, Laura also directs readers to resources, such as EDUCAUSE's Learning Space Rating System. Finally, the "Conference Report" section features a summary of a 2021 workshop on supporting cannabis entrepreneurs. This report, written by Steven M. Cramer, Morgan Ritchie-Baum, and Andrea Levandowski, notes that the pandemic forced this workshop to be held online. The research strategies and resources highlighted by the authors are extremely useful given the growing number of businesses in this space, and the complexity of locating reliable data on this fragmented industry. 